\section{Commentary: Fontan physiology and special consideration for lobectomy}

\author{
Tyler S. Wahl, MD, MSPH, and Benjamin Wei, MD
}

Nagayama and colleagues ${ }^{1}$ present an interesting technical case of anatomic lung resection for a primary lung malignancy in a patient with Fontan physiology. The patient of interest was diagnosed with pulmonary atresia and an intact ventricular septum having a hypoplastic tricuspid valve and right ventricle. The authors describe a remote left modified Blalock-Taussig palliation shunt from the left subclavian artery to left pulmonary artery placed during infancy presumably for elevated pulmonary vascular resistance (PVR). The authors do not mention whether a partial cavopulmonary shunt was fashioned before conducting total cavopulmonary connection (TCPC). Preoperative imaging revealed a TCPC with the superior vena cava connected directly to the right pulmonary artery and the inferior vena cava connected to the right pulmonary artery via an intra-atrial lateral tunnel. The modified Blalock-Taussig shunt was found to be occluded; it is unclear whether the shunt was intentionally ligated during the TCPC procedure or occluded over time. A cavopulmonary shunt is indicated once the PVR is reduced to $<4$ Wood Units $/ \mathrm{m}^{2}$ and any BT shunt taken down or ligated at this time to decrease the volume load of the systemic ventricle.

Although the patient was unlucky to develop lung cancer at age 26 years, he was fortunate that it occurred in the left lung. Due to a hypoplastic left pulmonary artery, perfusion to the left lung was minimal and the investigators correctly judged that a left upper lobectomy would not impair the

From the Division of Cardiothoracic Surgery, University of Alabama at Birmingham Medical Center, Birmingham, Ala.

Disclosures: The authors reported no conflicts of interest.

The Journal policy requires editors and reviewers to disclose conflicts of interest and to decline handling or reviewing manuscripts for which they may have a conflict of interest. The editors and reviewers of this article have no conflicts of interest.

Received for publication Jan 5, 2021; revisions received Jan 5, 2021; accepted for publication Jan 7, 2021; available ahead of print Jan 10, 2021.

Address for reprints: Benjamin Wei, MD, Division of Cardiothoracic Surgery, University of Alabama at Birmingham, Zeigler Research Building 701, 1720 2nd Ave, S, Birmingham, AL 35294 (E-mail: bwei@uab.edu).

JTCVS Techniques 2021;6:166

2666-2507

Published by Elsevier Inc. on behalf of The American Association for Thoracic Surgery. This is an open access article under the CC BY-NC-ND license (http:// creativecommons.org/licenses/by-nc-nd/4.0/).

https://doi.org/10.1016/j.xjtc.2021.01.007

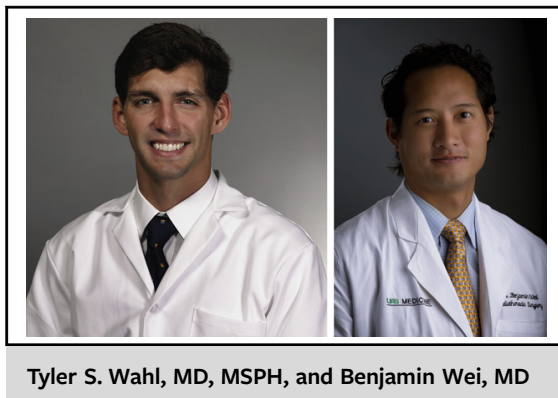

CENTRAL MESSAGE

Anatomic lung resections are feasible among select patients with Fontan physiology through careful consideration.

patient's Fontan circulation. What if the lesion had been located in the right lung? Concerns for increased PVR following lobectomy provoking Fontan failure are valid ${ }^{2,3}$ but theoretical given a paucity of literature in this specific population. A right middle, upper, or lower lobectomy may evoke varying effects, perhaps in a progressive fashion, respectively, on PVR and Fontan circulation either at rest or with exertion. How would even a lesser right-sided resection, such as wedge resection or segmentectomy, be tolerated in a patient with a Fontan circulation? There are little data on the topic. This unique case report should prompt thoracic surgeons to refamiliarize themselves with physiologic considerations among patients who have undergone palliative shunts. As life expectancy increases among this patient population, more survivors of congenital heart disease may require thoracic surgical intervention for malignancies of the chest. ${ }^{4,5}$

\section{References}

1. Nagayama K, Kitano K, Yoshiyasu N, Nakajima J. Lobectomy for lung cancer in a patient with Fontan circulation: a case report. J Thorac Cardiovasc Surg Tech. 2021;6:163-5.

2. Van Mieghem W, Demedts M. Cardiopulmonary function after lobectomy or pneumonectomy for pulmonary neoplasm. Respir Med. 1989;83:199-206.

3. Nishimura H, Haniuda M, Morimoto M, Kubo K. Cardiopulmonary function after pulmonary lobectomy in patients with lung cancer. Ann Thorac Surg. 1993;55: $1477-84$.

4. Frock BW, Jnah AJ, Newberry DM. Living with tricuspid atresia: case report with review of literature. Neonatal Netw. 2017;36:218-28.

5. Verheugt CL, Uiterwaal CS, Vaartjes I, van der Velde ET, Zomer AC, Meijboom FJ, et al. Chance of surgery in adult congenital heart disease. Eur J Prev Cardiol. 2017;24:1319-27. 